\title{
Experimental and Numerical Investigations of the Shear Behavior of Binary Particle Blends
}

\author{
Jiecheng Yang ${ }^{1}$, Poom Bunchatheeravate ${ }^{2}$, Subhash Thakur ${ }^{2}$, Joseph Bullard ${ }^{2}$, and \\ Jennifer Sinclair Curtis ${ }^{3}$ \\ ${ }^{1}$ University of California Davis \\ ${ }^{2}$ Vertex Pharmaceuticals Incorporated \\ ${ }^{3}$ Universtity of California, Davis
}

May 8, 2020

\begin{abstract}
In this study, a Schulze Ring Shear Tester and the Discrete Element Method (DEM) are employed to investigate the effect of polydispersity on the binary shear flows. Both experimental results and DEM simulations show that the pre-shear stresses are greater for binary blends than for monodispersed particles. The flowability of these mixtures is strongly affected by the solid fraction, with minimal flow function values correlating to maximum packing fraction. However, minimum flow function values are not observed at the same packing fractions where the maximum pre-shear stress occurs. The powder friction has a slightly higher contribution to powder strength than powder adhesion, and the frictional component follows the same trend as shear stress with mixture composition. Using DEM, it is demonstrated that the addition of small adhesive particles reduces the averaged angular velocity of the larger particles, which makes a contribution to the larger shear stress for binary blends.
\end{abstract}

\section{Experimental and Numerical Investigations of the}

\section{Shear Behavior of Binary Particle Blends}

Jiecheng Yang ${ }^{*}$, Poom Bunchatheeravate ${ }^{2}$, Subhash C. Thakur ${ }^{2}$, Joseph W. Bullard ${ }^{2}$, and Jennifer S. Curtis $^{1}$

${ }^{1}$ Department of Chemical Engineering, University of California Davis, Davis, CA 95616, USA

${ }^{2}$ Vertex Pharmaceuticals Incorporated, Boston, MA 02210, USA

*corresponding author

Abstract: In this study, a Schulze Ring Shear Tester and the Discrete Element Method (DEM) are employed to investigate the effect of polydispersity on the binary shear flows. Both experimental results and DEM simulations show that the pre-shear stresses are greater for binary blends than for monodispersed particles. The flowability of these mixtures is strongly affected by the solid fraction, with minimal flow function values correlating to maximum packing fraction. However, minimum flow function values are not observed at the same packing fractions where the maximum pre-shear stress occurs. The powder friction has a slightly higher contribution to powder strength than powder adhesion, and the frictional component follows the same trend as shear stress with mixture composition. Using DEM, it is demonstrated that the addition of small adhesive particles reduces the averaged angular velocity of the larger particles, which makes a contribution to the larger shear stress for binary blends.

Keywords: Binary shear flows; Ring shear test; Discrete Element Method 


\section{Introduction}

Fundamental understanding of the flow behavior of bulk solids is essential for granular material handling and the design of relevant industrial processes and equipment, such as hoppers, silos and blenders. The Schulze Ring Shear Tester (SRST) is one of the most popular testers of bulk solids flow properties and it can measure the shear stresses under various normal stresses. Therefore, the internal friction angle, wall friction angle, unconfined yield strength, bulk density and flow function of the tested granular material can also be provided ${ }^{1,2}$. In addition, numerical approaches such as Discrete Element Method (DEM) are also increasingly applied to investigate the flow behavior of granular materials. Detailed information at the individual particle level, such as the particle position, particle velocity and forces exerted on the particle, can be obtained from DEM simulations, which is helpful for exploring the mechanisms of particle behavior ${ }^{3,4}$.

Both previous experimental and numerical research has shown that the flow behavior of bulk solids could be influenced by many factors. The effect of particle shape was investigated by Baran et al. ${ }^{5}$ and results shown that the shear stress for spherical particles was considerably lower than that of aspherical particles. Shear stress for aspherical particles were found larger than that for spherical ones, for both monodisperse ${ }^{6}$ and binary mixtures ${ }^{7}$. The internal friction angle was increased by preventing particle rotation ${ }^{8}$. The shear stress was also found to increase with increasing coefficient of friction between particles ${ }^{2,5,9}$. On the other hand, the shear cell size, shear rate, particle shear modulus, particle Poisson's ratio, the coefficient of restitution and particle-particle cohesion were argued to have insignificant influence on the shear stress ${ }^{2,5,9}$.

Among the factors affecting the flow properties of bulk solids, particle size polydispersity is known to have an important effect on particle flow behavior ${ }^{7,10-12}$. Rule of Mixture (ROM) approaches are often employed in predicting the flow behavior of binary or higher-order powder systems. In ROM frameworks, the predicted properties are calculated using the properties of constitutive components, which are weighted by their composition of the final blend using various averaging techniques. For example, the flow function coefficient for binary mixtures of acetaminophen and starch were found to decrease with increasing mass fraction of acetominophen, which exhibits poorer flow behavior than starch as a pure material ${ }^{13}$. For binary systems, any property predicted using ROM will always fall between those of the raw components. However, this approach ignores many complex interactions inherent to mixtures of particles, and even seemingly simple systems deviate from trends predicted by ROM approaches.

Analogs to the systems evaluated here have previously been shown to exhibit behavior that cannot be explained by simple ROM approaches. Vallejo ${ }^{12}$ conducted laboratory tests on mixtures of large $(5000 \mu \mathrm{m})$ and small $(400 \mu \mathrm{m})$ glass beads to evaluate the shear strength of the resultant blends, and reported a strong dependence on the relative concentration of the mass fraction of large and small particles. In the range of 40-70\% mass fraction of large particles, shear strength decreased with decreasing fraction of large particles. However, shear strength was controlled by the frictional resistance of the large particles if the mass fraction of large particles exceeded $70 \%$, whereas the effect of small particles dominated when below $40 \%$. Vallejo argued that these limits resulted from changes in mixture porosity and particle configuration.

In order to evaluate the effect of particle size polydispersity on the flow behavior, experiments are set up to obtain shear stress data in a simple flow configuration (SRST) using a model system of well-characterized, binary mixtures of spherical glass beads. By varying the ratio of small to large particles in the system, this approach facilitates a detailed study of the effect of polydispersity on the flow behavior of particle mixtures. Furthermore, in order to investigate the fundamental underpinnings associated with the flow behavior (i.e. shear stress trend), DEM is applied to model the shear flows of such mixtures in the ring shear cell. First, the experimental data are used to validate the model predictions. Then, via DEM, the effects of particle rotation, particle contact type, particle contact number and force network are investigated. By analyzing these effects, potential underlying mechanisms giving rise to the variation in mixture flowability are proposed and explored. 


\section{Experimental SRST}

\subsection{Material}

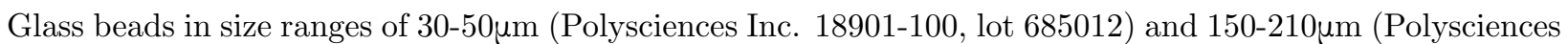
Inc. 05483-250, lot A760996) were acquired from Polysciences Inc. A particle density of $2500 \mathrm{~kg} / \mathrm{m}^{3}$ is used in both the DEM simulation and experimental analysis, consistent with averaged reported values from vendor specifications.

Prior to testing, samples were screened using a \#100 US standard sieve (150um opening). Images of each bead type were taken at 200x magnification using a Keyence VHX-2000 optical microscope. Binary blends of small and large glass beads were prepared at ratios of 3:1, 1:1, and 1:3 on a mass basis, and prepared at a $30 \mathrm{~g}$ scale. Weighed and screened materials were transferred to a $135 \mathrm{ml}$ glass container and mixed using a Turbula mixer at $32 \mathrm{rpm}$ for $5 \mathrm{~min}$.

\subsection{Shear testing}

Ring shear testing of each blend was performed on the Schulze RST-XS using the XS-MV4 shear cell. The shear cell is annular in shape with an inner diameter of $32 \mathrm{~mm}$ and an outer diameter of $64 \mathrm{~mm}$. The initial gap between the base and the lid is $4 \mathrm{~mm}$; the size of this gap decreases as pressure is applied to the shear cell and particle mixtures are compressed. The shearing bar of the XS-MV4 cell is pyramidal in shape and covers the surface of both the base and the lid.

Shear measurements were performed using a shear rate of $0.004 \mathrm{~s}^{-1}$ and a 2000 Pa pre-shear load, with subsequent consolidation loads of 400, 700, 1000, 1300, and $1600 \mathrm{~Pa}$. For this work, the shear data and the solid fraction data taken at the pre-shear condition were used to compare to the DEM simulation. Two replicates were performed for each blend condition, with new particle mixtures prepared to generate the replicate data.

The segregation of the binary blend is very apparent. After blending, there are regions in the glass jar where the small and large beads are separated. Given the large size ratio (approximately 4.5), it is very difficult to mix the particle into a random mixture. Segregation is an inherent factor to the shear test and it was not possible to completely eliminate from our experiment. The shear cell was filled by taking multiple scoops of blend from the bulk mixture, with each scoop taken from a random location within the blending vessel. Segregation is observed even when filling the shear cell, the area of segregated particle can be seen when preparing the shear cell. Figure 1 presents an image taken on the surface of the shear cell before testing. All shear tests were performed on the material as is. Due to the method of fill for the shear cell (scooping from a mixture prone to segregation), the content of the shear cell is emptied out after the shear test. The content is again sieved through a \#100 US standard sieve, separating them into smaller ( $<150 \mu \mathrm{m})$ and larger ([?]150um) segments. The mass of each sample is then determined to verify the mixture composition.

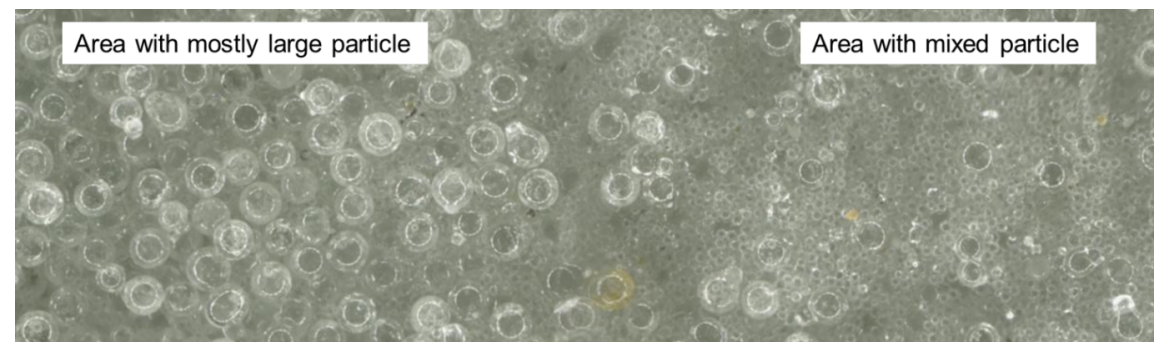

Figure 1. Segregation observed when preparing the XS-MV4 cell 
To observe the behavior of individual particles in the shear cell, an optical microscope with a 200x magnification lens (Keyence VH-Z20R) was positioned above the shear cell, as shown in Figure 2. The resulting images and videos detail the motion of particles visible through the gap between the base of the shear cell and the lid. Although this approach does not directly capture the motion of particles within the bulk system inside the shear cell, it does provide an understanding of particle behavior on the free surface of the blend.

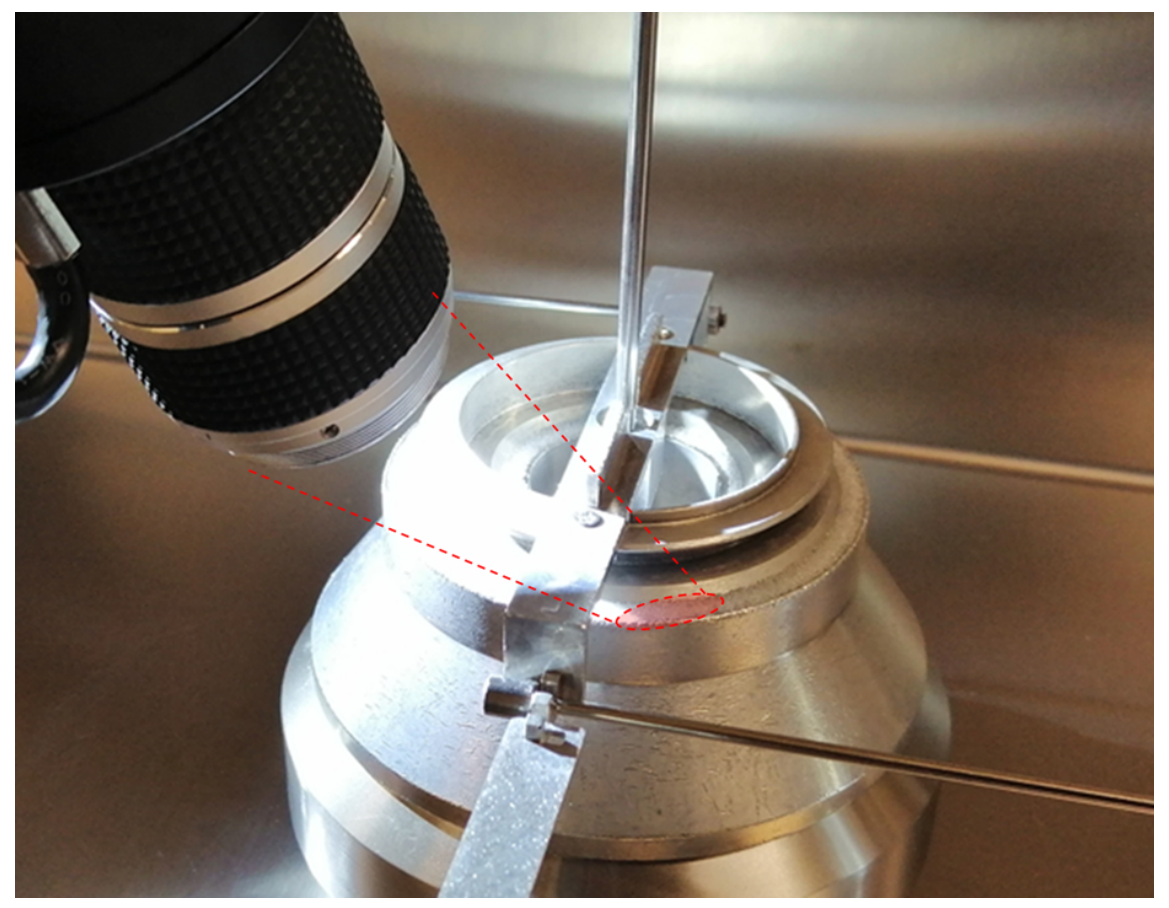

Figure 2. Video capture of the shearing glass beads

\subsection{Data analysis of shear test results}

The key outputs from ring shear measurements analyzed for each binary blend include pre-shear stress $\left(\tau_{\text {pre }}\right)$, unconfined yield strength $\left(\sigma_{\mathrm{u}}\right)$, flow function coefficient $(\mathrm{FFc})$, packing density, and linearized friction angle $(\varphi)$. The pre-shear stress, $\tau_{\text {pre }}$, is the first point of measurement on the material, and represents the shear stress required to achieve steady state flow at a specified pre-shear load, $\sigma_{\text {pre }}$. In this work, $\sigma_{\text {pre }}$ was fixed at $2000 \mathrm{~Pa}$ for all systems evaluated. The unconfined yield strength, $\sigma_{\mathrm{u}}$, is the stress required to fail the material in an unconfined state after subjected to major principal stress. This parameter gives an indication of the overall strength of the powder. A physical representation of these parameters are in Figure 3.

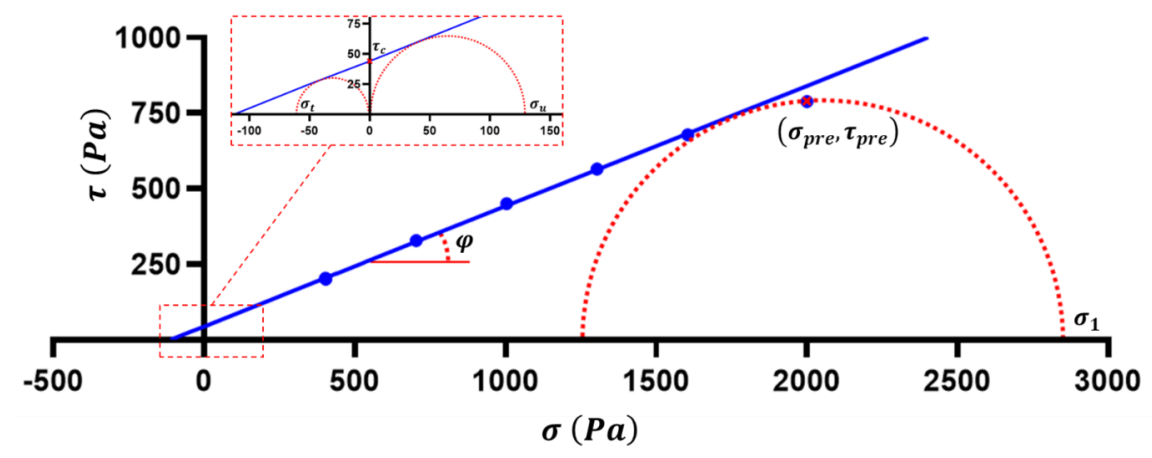


Figure 3. Extracted parameters from the yield loci.

In order to better understand the contribution of pure friction and adhesion to the unconfined strength, it can be decomposed into tensile strength $\left(\sigma_{\mathrm{t}}\right)$ and internal angle of friction $(\varphi)$ using the equation ${ }^{14,15}$ as:

$\sigma_{u}=\frac{1+\sin \varphi}{1-\sin \varphi} \sigma_{t}(1)$

The equation assumes linearized yield loci ( $\tau$ and $\sigma$ plot).

The linearized friction angle represents the pure frictional component of the material. On the other hand, the tensile strength $\left(\sigma_{t}\right)$ represents the adhesive component of the material, which is the strength required to 'pull' the material apart as shown in Figure 4. The Flow function coefficient (FFc) is the ratio of the major principal stress to the unconfined yield strength. Increasing values of FFc relate to better flowability of the powder.
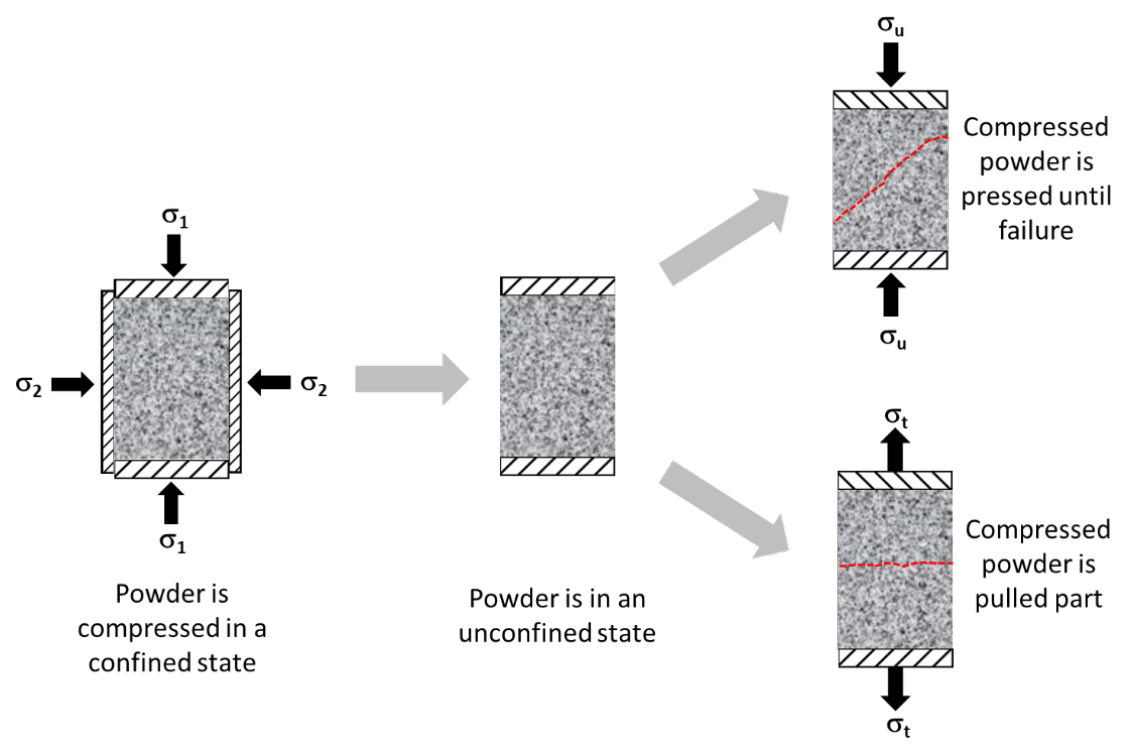

Figure 4. Unconfined yield strength and tensile strength.

\section{Numerical method and simulation conditions}

\subsection{Numerical method}

The translational and rotational motion of a particle is modeled by DEM using Newton's second law as ${ }^{16}$ :

$m_{i} \frac{\mathrm{d} u_{i}}{\mathrm{~d} t}=\sum_{j}\left(F_{\mathrm{ij}}^{n}+F_{\mathrm{ij}}^{s}\right)+m_{i} g(2)$

$I_{i} \frac{\mathrm{d} \omega_{i}}{\mathrm{~d} t}=\sum_{j} R_{i} \times F_{\mathrm{ij}}^{s}(3)$

where $u_{i}$ and $\omega_{i}$ are the translational and angular velocity of particle and $m_{i}$ and $I_{i}$ are the mass and moment of inertia of particle . $F_{\mathrm{ij}}^{n}$ and $F_{\mathrm{ij}}^{s}$ are the normal and tangential forces acting on particle. Particle adhesion/cohesion is considered by implementing the adhesive/cohesive contribution into $F_{\mathrm{ij}}^{n}$ and $F_{\mathrm{ij}}^{s}$ through JKR theory ${ }^{17}$ and the Thornton and Yin model ${ }^{18,19}$.

\subsection{Simulation conditions}


Large and small glass bead particles, described by the median sizes of the actual particles, 180 and $40 \mu \mathrm{m}$ respectively, are used in the current study. Both particles are assumed to be spherical and possess the same material properties. Initially, a number of large spheres and small spheres are randomly generated in the simulation domain, periodic in two dimensions, with a specified mixture composition. The size of the domain is $30 d_{S} \times 30 d_{S} \times 15 d_{S}$, in which $d_{S}$ is the diameter of the small particle. Based on our previous work ${ }^{2}$, it is believed the simulated shear stress results are independent of the domain size, although the domain size is smaller than the shear cell size. Cases with mass fraction of large particles ranging from 0 to 1 are conducted. After all particles deposit on the bottom wall of the DEM shear cell and achieve a negligible velocity, a normal pressure $\left(2000 \mathrm{~Pa}\right.$ ) is specified on the top wall and a velocity (shear rate of $0.2 \mathrm{~s}^{-1}$ ) is applied to the bottom wall to start the shearing process as shown in Figure 5. The shear rate is higher than the experimental one to reduce the computational expense but it also assures a quasi-static state in which the shear stress is independent of shear rate ${ }^{2,20}$. Shearing bars (blades) on both top and bottom walls are also created to mimic the configuration of the realistic shear cell and prevent the sliding of particles. Simulations run sufficient time steps until the shear process reaches a steady state and the stresses are nearly constant with small fluctuations. The particle properties in the simulations are given in Table 1.

$$
\downarrow \sigma_{p r e}=2000 \mathrm{~Pa}
$$

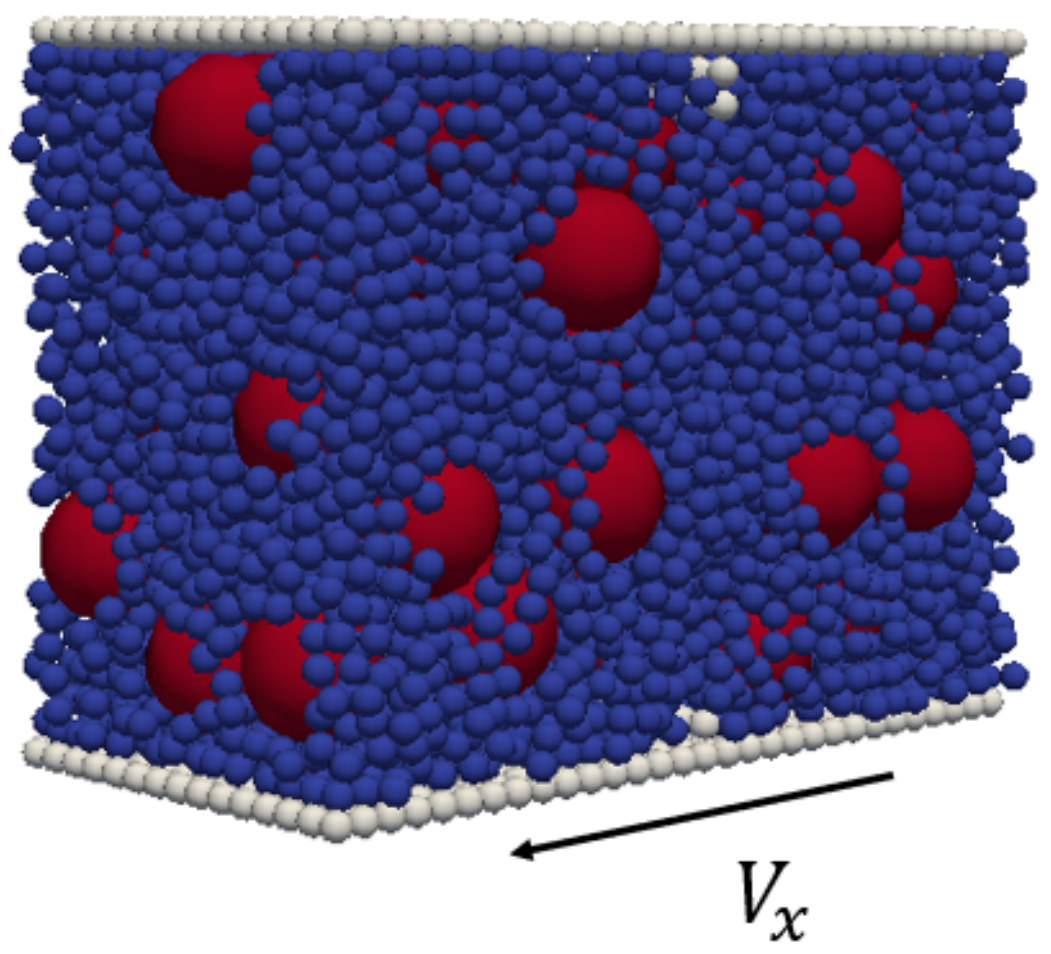

Figure 5. Sketch of the DEM shear cell.

Table 1. Particle Properties.

\begin{tabular}{ll}
\hline Properties & Values \\
\hline Large particle diameter $(\mu \mathrm{m})$ & 180
\end{tabular}




\begin{tabular}{ll}
\hline Properties & Values \\
\hline Small particle diameter $(\mu \mathrm{m})$ & 40 \\
Particle density $\left(\mathrm{kg} / \mathrm{m}^{3}\right)$ & 2500 \\
Young's modulus $(\mathrm{GPa})$ & 16 \\
Poisson's ratio & 0.22 \\
Coefficient of restitution & 0.92 \\
Coefficient of sliding friction & 0.3 \\
Surface energy $\left(\mathrm{J} / \mathrm{m}^{2}\right)$ & 0.005 \\
\hline
\end{tabular}

\section{Results and discussion}

\subsection{Experimental data}

\subsubsection{Relationship between flowability and packing density}

Figure 6 shows the relationship between FFc and packing density as a function of blend composition. It can be observed that the FFc of any binary mixture is lower than that of each of the primary components of the system. A similar phenomenon was observed by Vallejo ${ }^{12}$, who attributed this behavior to the increase in solid fraction of the blend and particle configuration. That work investigated relatively larger sizes of glass bead mixtures, with nominal sizes of small and large particles reported as 400 and $5000 \mu \mathrm{m}$, respectively, and did so at consolidation stresses between 6 and 40 times larger than those employed here.

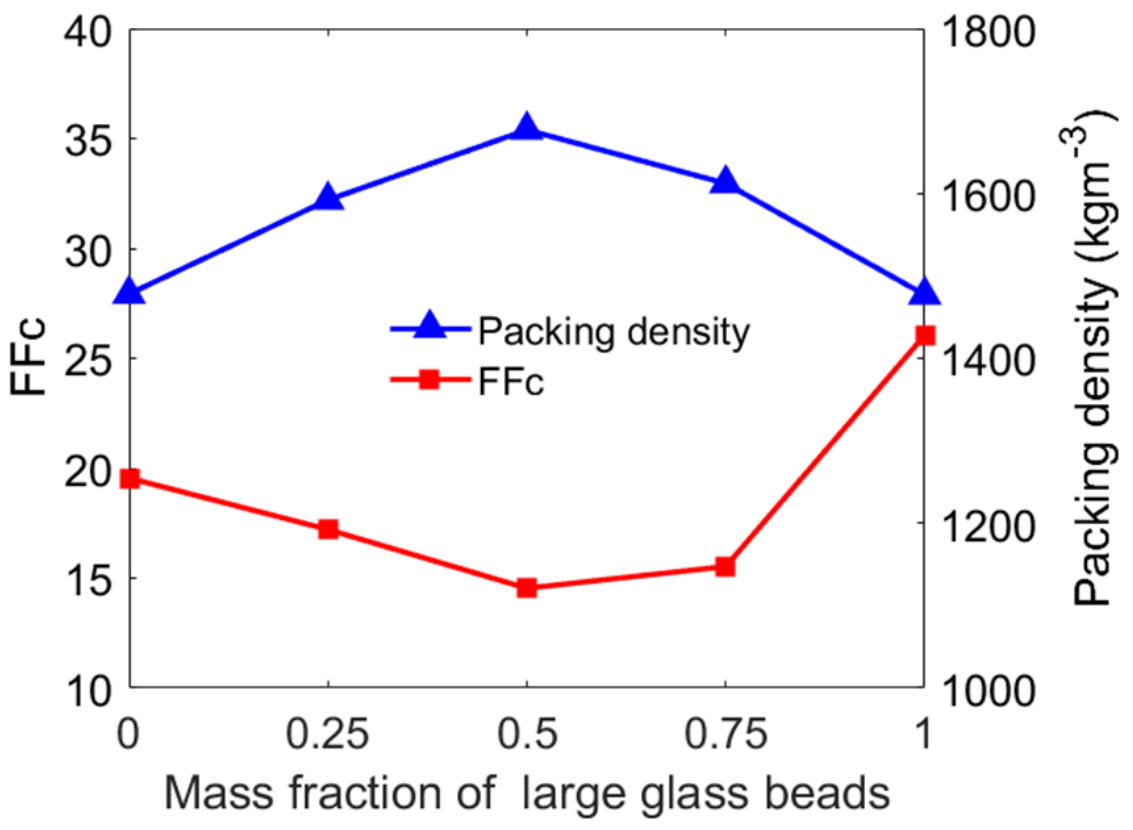

Figure 6. Flow function coefficient and packing density of the binary blends measured using the SRST.

While comparing FFc and packing density, indeed a correlation can be found as suggested by Vallejo ${ }^{12}$. This confirms that for a mixture of similar materials such as glass beads, packing has a significant influence on powder flowability. Increased packing is associated with decreased flowability and lower FFc. The contribution of adhesion and friction to FFc are further investigated. 


\subsubsection{Relationship between tensile strength and packing density}

Figure 7 shows the key output from the shear test with its interrelationships. Figure 7 (a) shows that the FFc relationship mirrors that of the unconfined yield strength $\left(\sigma_{\mathrm{u}}\right)$ relationship. In theory, the total strength of the material should be the summation of the adhesion component and the frictional component of the system. The adhesive or tensile component $\left(\sigma_{t}\right)$ is shown in Figure $7(\mathrm{~b})$. It is found that tensile strength $\left(\sigma_{t}\right)$, which represents the stress required to fail the powder in tension, correlates with the degree of packing of the powder. As the degree of packing of the powder increases, greater forces are required to separate particles from their neighbors, increasing the overall tensile strength of the powder. The results are consistent with Rumpf's theory of tensile strength ${ }^{21}$.

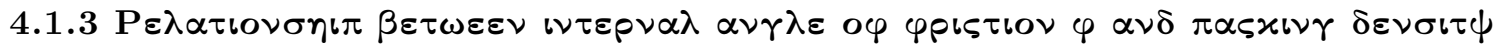

We further explore the relationship between the internal angle of friction $\varphi$ and the packing density (Figure 7 (c)); $\varphi$ shows the most deviation with the packing density. While $\varphi$ shows a linear relationship with the packing density for $0 \%$ to $50 \%$ large glass beads, the results deviate from the packing density as the large glass bead fraction is increased from $50 \%$ to $75 \%$. This seems counterintuitive, as $\varphi$ still increases with decreasing packing density. On further increase of large glass beads beyond $75 \%$, the $\varphi$ decreases with decreasing packing density. This behavior is explored in sections $4.2-4.4$ by simulating steady state shearing using DEM.

The steady state shear stress ( $\tau_{\text {pre }}$ ) correlates well with $\varphi$ (see Fig $7(\mathrm{c})$ ). This can be described mathematically using the Mohr Coulomb failure criterion:

$\tau=\sigma \tan (\varphi)+\tau_{c}$

Where $\tau_{\mathrm{c}}$ is the cohesion term which is directly related to $\sigma_{\mathrm{t}}$ by a trigonometric relationship. For glass beads, the $\left(\sigma_{\text {pre }}, \tau_{\text {pre }}\right)$ point is colinear to the yield loci. Based on equation 4 , the $\tau$ term is dominated by $\sigma \tau \alpha \nu(\varphi)$; therefore, the $\tau_{\text {pre }}$ is $\varphi$ weighted by $2000 \mathrm{~Pa}$.

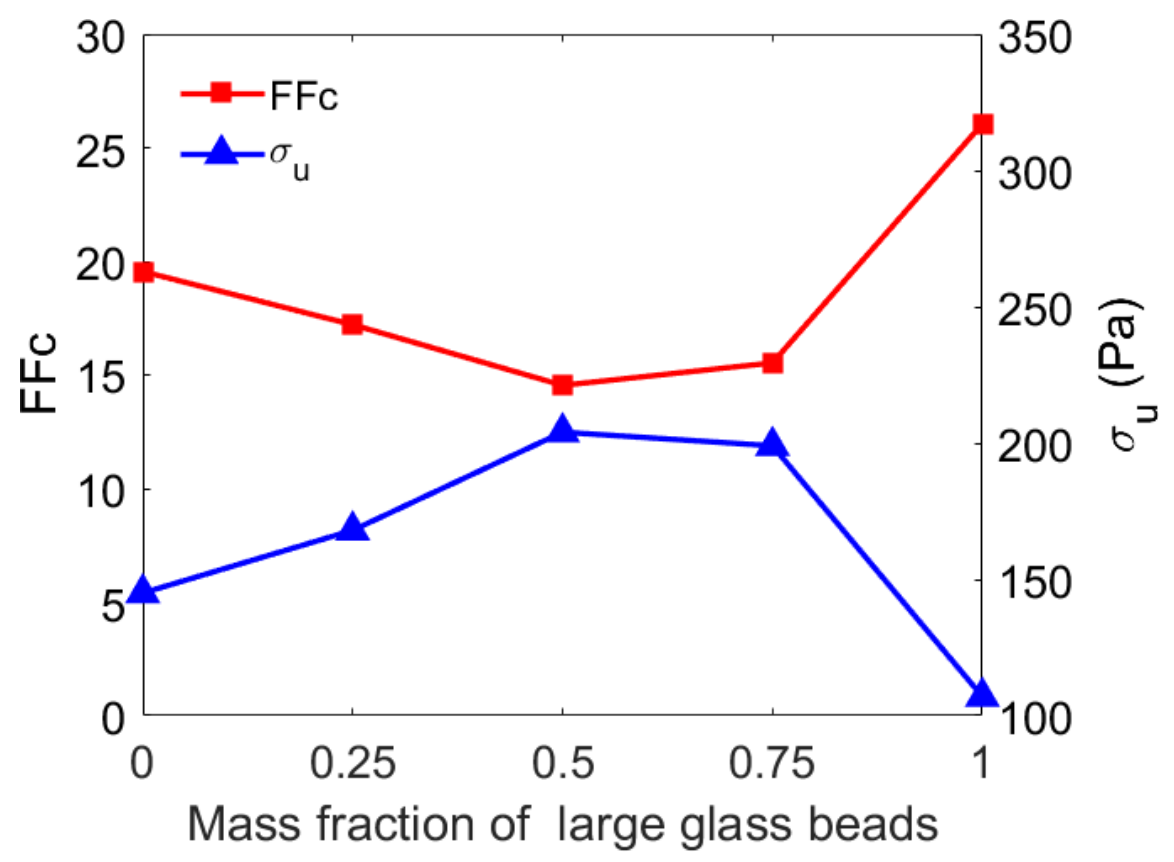

a) 


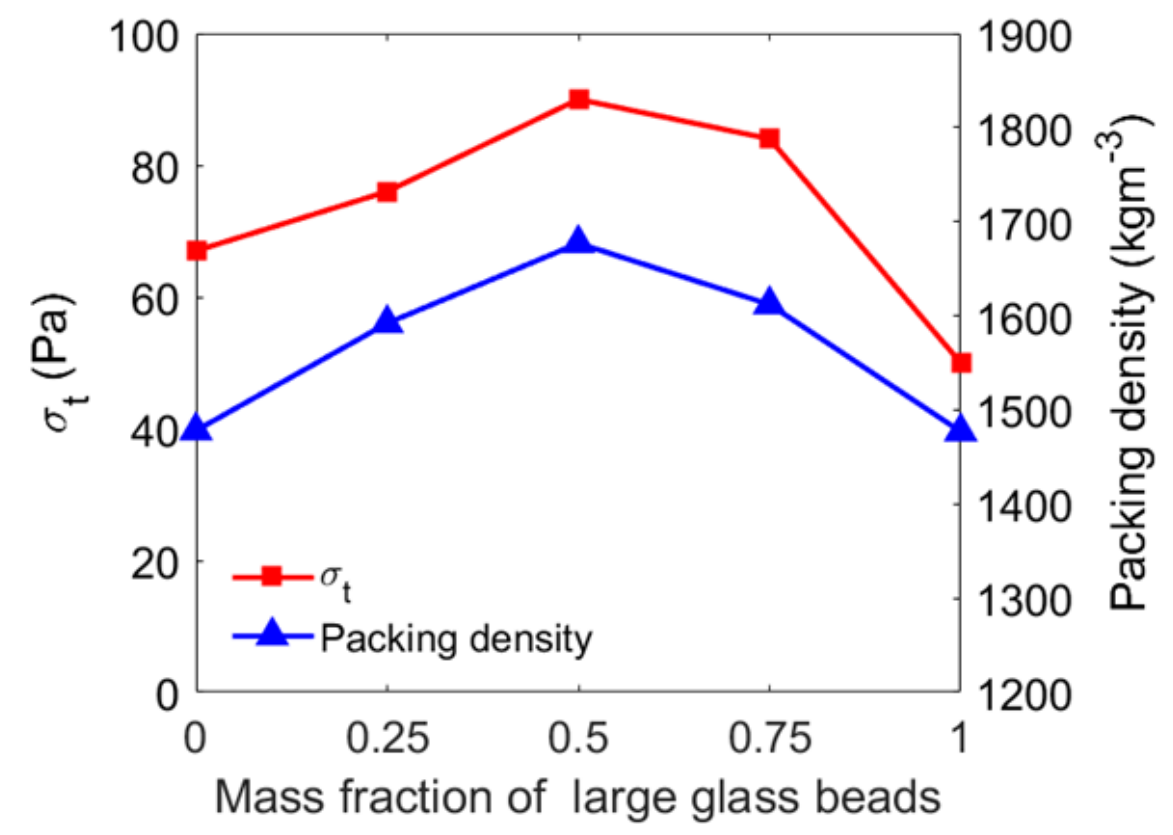

b)

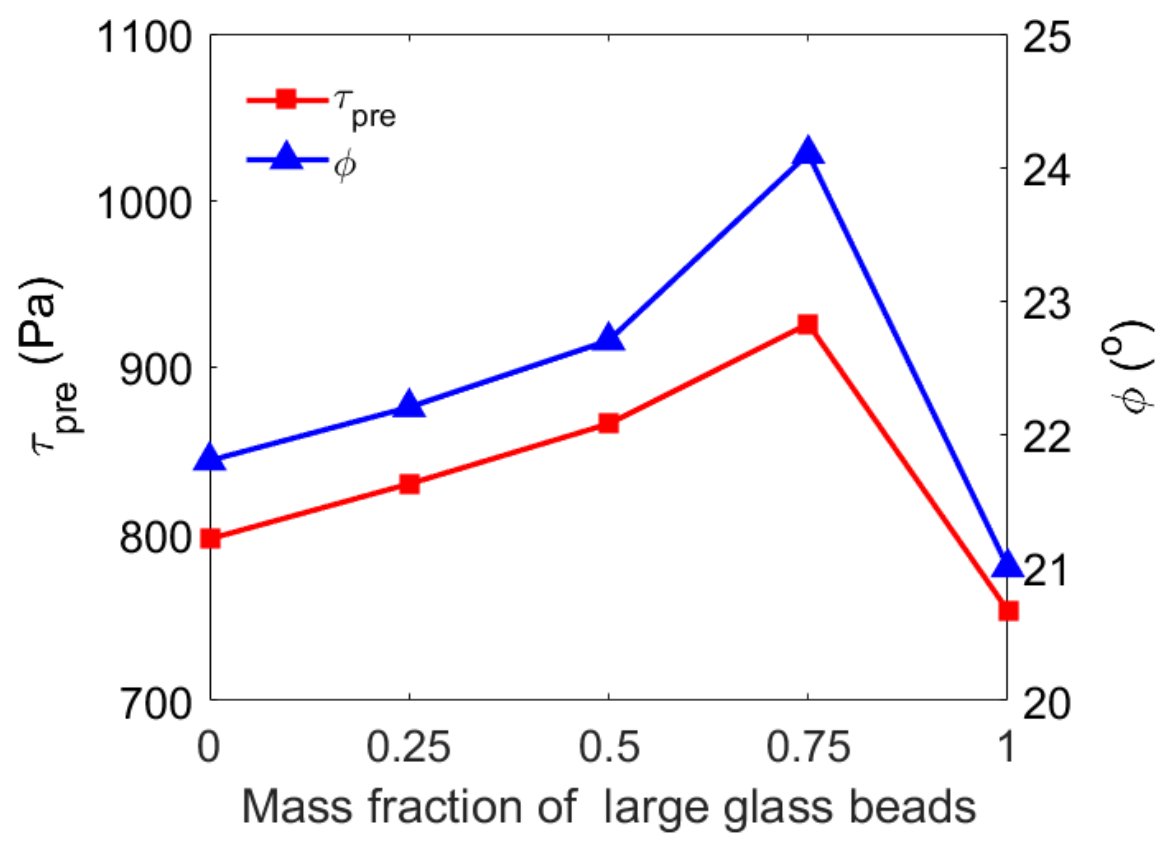

c)

Figure 7. Plot of the key experimental output from the SRST. (a) FFc and $\sigma_{\mathrm{u}}$, (b) $\sigma_{\mathrm{t}}$ and packing density, and (c) $\varphi$ and $\tau_{\text {pre }}$. 


\subsubsection{Relative contribution of tensile strength and friction on unconfined yield strength}

Next, the relative contribution of the tensile and frictional components on the unconfined yield strength are explored. The stress contribution due to the frictional component $\sigma_{f}$ is calculated by subtracting tensile strength from the unconfined yield strength:

$\sigma_{f}=\sigma_{u}-\sigma_{t}(5)$

It is important to note that this frictional component is different from the internal angle of friction and the shear stress. It is a fictitious contribution of friction to unconfined yield strength in the normal direction.

Figure 8 shows the relationship between the frictional and tensile contributions to the total unconfined yield strength. Both the friction and tensile strength contribute to the unconfined yield strength, and the contribution of friction is slightly higher than that of tensile strength. It is also noted that the frictional strength follows the trend of internal angle of friction and $\tau_{\text {pre }}$ as shown in Figure $7 \mathrm{c}$.

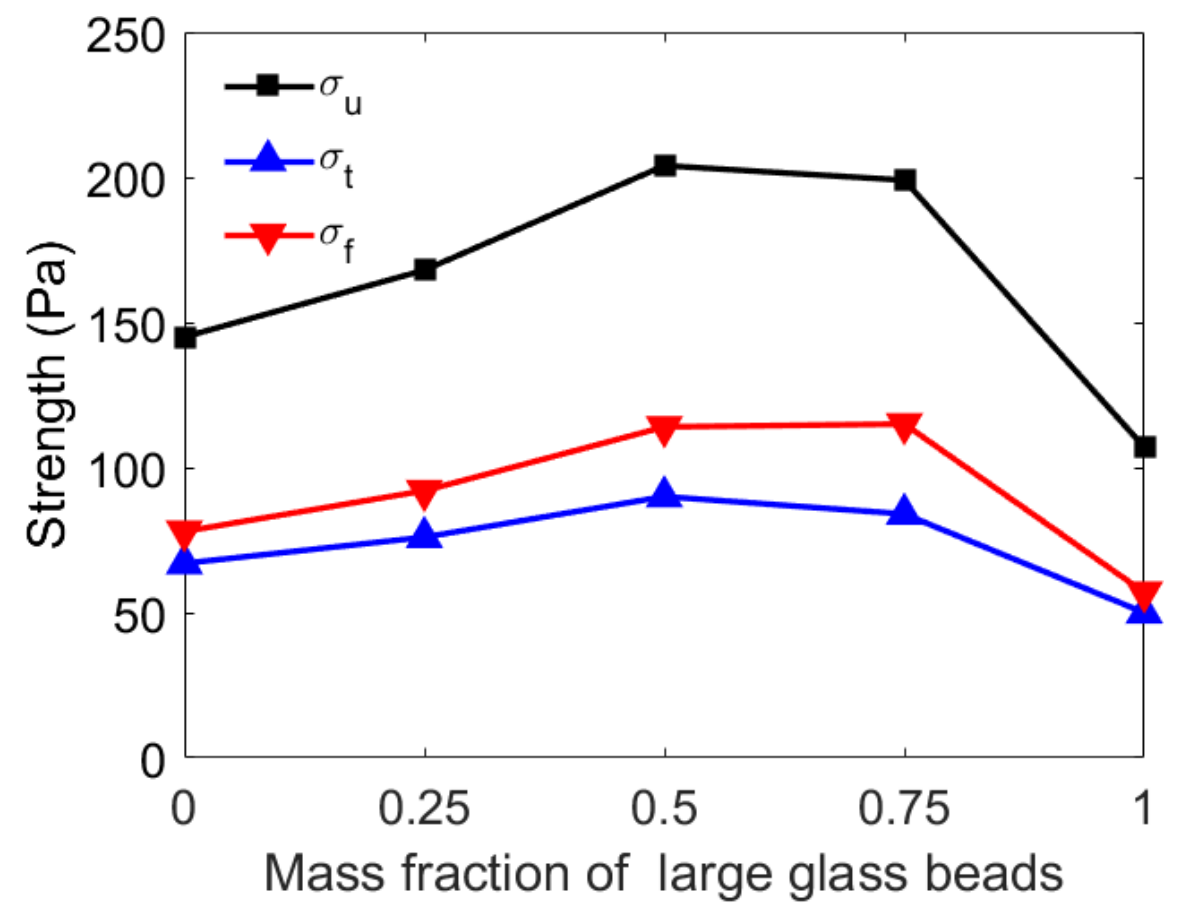

Figure 8. Contribution of friction and tensile strength on unconfined yield strength.

\subsection{Comparison of experimental and DEM results}

At the 2000 Pa pre-shear load, the DEM predictions for the shear stress at steady state are compared to the experimentally measured $\tau_{\text {pre }}$. This comparison is shown in Figure 9; higher $\tau_{\text {pre values represent }}$ poorer flowing systems. The predicted stresses associated with the binary blends are larger than those of the monodispersed particles, exhibiting the same trend as the experimental results. However, the DEM predictions for $\tau_{\text {pre }}$ are lower than the experimental values, possibly due to neglecting the size distribution associated with the large and small glass beads.

\section{Hosted file}

image12.emf available at https://authorea.com/users/319476/articles/449200-experimental-andnumerical-investigations-of-the-shear-behavior-of-binary-particle-blends 
Figure 9. Comparison of the $\tau_{\text {pre }}$ from experiments and DEM simulations.

In order to compare the experimental packing density with the DEM predictions, the experimental packing density is converted to solid fraction. Solid fraction is calculated by dividing the packing density with the true density of the glass beads, i.e. $2500 \mathrm{~kg} / \mathrm{m}^{3}$. The variation of solid fraction with composition is shown in Figure 10. The solid fraction in both the experiment and DEM simulations is calculated by recording the position of the top boundary under the same 2000 Pa pre-shear load. For both sizes of monodispersed spherical beads, the predicted and measured solid fraction is similar with a value around 0.6. In addition, the solids fraction for the binary mix is higher than that of the monodispersed particles, similar to what was observed by Vallejo ${ }^{12}$. The DEM predictions of solid fraction are able to reproduce the experimental measurements quite well.

\section{Hosted file}

image13.emf available at https://authorea.com/users/319476/articles/449200-experimental-andnumerical-investigations-of-the-shear-behavior-of-binary-particle-blends

Figure 10. Comparison of the solid fraction from experiments and DEM simulations.

\subsection{Large particle rotation}

Videos taken during the shear tests (available in the supplementary information) reveal drastically different macroscopic flow behavior for the monodispersed and binary mixtures. For the monodispersed smaller sized beads, a bulk motion of the system, with coordinated movement of particles in a wave-like fashion is observed. For the monodispersed larger size beads, a start-stop and rotational motion of individual particles is observed within the bulk. However, these individual movements of large particles are not observed in the video with 0.50 large glass bead mass fraction, suggesting that at lower concentrations, small particles hinder the ability for the larger particles to rotate. The 0.75 system exhibited the highest degree of segregation of all the mixtures tested. For the 0.75 system, in regions of low levels of particle segregation, the macroscopic flow behavior of the binary mixture resembles that of the 0.5 system. However, in regions of high levels of particle segregation, with a higher concentration of large glass beads near the surface, rotation of individual large glass beads is observed. Time-lapse images of the video for the 0.75 system are extracted and shown in Figure 11. In the images, a few particles are outlined to indicate their movement with time. From these images, it is evident that the highlighted large glass bead is rotating. As the larger glass bead rotates, multiple small glass beads on the surface of the larger particle can be identified. This behavior indicates that the addition of small glass beads, even at low concentrations, can adhere to the larger glass beads.

While spinning movement is observed for the large particles, the small particles move as a bulk in a wavelike motion. Furthermore, for the 50:50 binary mixture, the larger particles show no evidence of spinning movement, and the bulk flow is similar to that of the small particles. Therefore, an explanation for the unique shear stress trend is proposed based on this observed macroscopic flow behavior. The hypothesis is that large particles can spin, rather than move transversally, minimizing the bed dilatation during shearing. And, the addition of smaller, more cohesive particles and the adhesion between large and small particles minimizes or prevents the spinning of the large particles. This, in turn, results in a larger shear stress of the binary blend required to induce flow. 


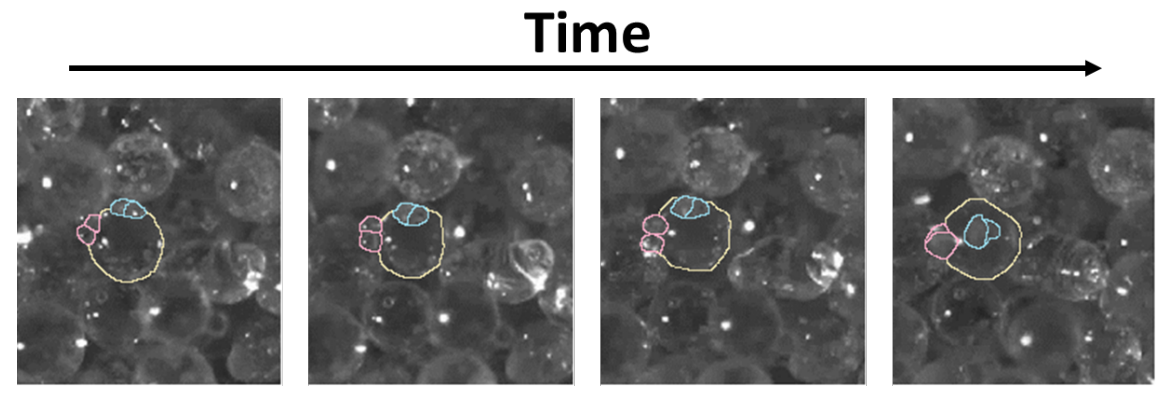

Figure 11. Time-lapse images of large particle rotation with two seconds between images

In order to verify this hypothesis, the angular velocities of the large particles in the various mixtures are examined via DEM simulations. Figure 12 shows the averaged angular velocity of the large particles for different blends. It is clearly found that the averaged angular velocity for monodispersed large particles is significantly higher than those of binary mixtures, demonstrating that the addition of smaller, more cohesive particles reduces the average angular velocity of the large particles. This reduction in angular velocity, making particle shearing more difficult, consequently leads to an increase in the shear stress of the binary particle mixture. While this reduced angular velocity will give rise to an increased binary shear stress, it is believed that the shear stress distribution of the binary mixture is a combined results of many factors including, but not limited to, the rotation of the larger particles. Therefore, the effect of particle interactions on the shear stress is further explored.

\section{Hosted file}

image15.emf available at https://authorea.com/users/319476/articles/449200-experimental-andnumerical-investigations-of-the-shear-behavior-of-binary-particle-blends

Figure 12. Averaged angular velocity of large particles for different blends.

\subsection{Particle interactions}

In addition to the large particle rotation, different particle mixtures may have different particle interactions that also contribute to the shear stress difference. The contact numbers for three contact types, i.e. the contact between large and large particles L-L, large and small particles L-S, and small and small particles S-S, are shown in Figure 13. While only L-L contacts and S-S contacts exist for monodispersed large and small particles, respectively, the number of S-S contact dominate the numbers of the other two types of contacts. The number of S-S contacts for the three binary mixtures decreases with increasing mass fraction of large particles, as a lower large particle mass fraction leads to a higher number of small particles and a higher number of S-S contacts.

\section{Hosted file}

image16.emf available at https://authorea.com/users/319476/articles/449200-experimental-andnumerical-investigations-of-the-shear-behavior-of-binary-particle-blends

Figure 13. Contact numbers for three contact types (L-L, L-S and S-S) for different mixtures.

The contact numbers for the three contact types for the different mixtures are normalized and shown in Figure 14. The L-L and L-S contact numbers are normalized by the number of large particles in the given mixture, and the S-S contact number is normalized by the number of small particles. From the perspective of normalized contact number, the L-S contact is the dominant type of contact for the binary mixtures, indicating that for the current particle size ratio of 4.5, the large particles in the binary mixtures are surrounded by small particles sticking to the surface. The normalized L-S contact number for the binary 
mixtures ranges from 45 to 12 and decreases with increasing mass fraction of large particles. The significant difference in normalized L-S contact number for various composition indicates that different composition has different contact structure. This is especially true for the contact structure around the large particles, which may also affect the motion of particles and contribute to the shear stress difference.

\section{Hosted file}

image17.emf available at https://authorea.com/users/319476/articles/449200-experimental-andnumerical-investigations-of-the-shear-behavior-of-binary-particle-blends

Figure 14. Normalized contact numbers for three contact types (L-L, L-S and S-S) for different mixtures.

In order to further explore the effect of particle interactions on the shear stress, detailed contact information is extracted from the DEM simulations to illustrate the transmission of force in the system. Contacts in a middle slice within the computational domain (one third of the thickness of the domain), as shown in Figure 15 , are displayed by lines that connect the centers between two contacted spheres. The force magnitude is represented by the thickness of the line.

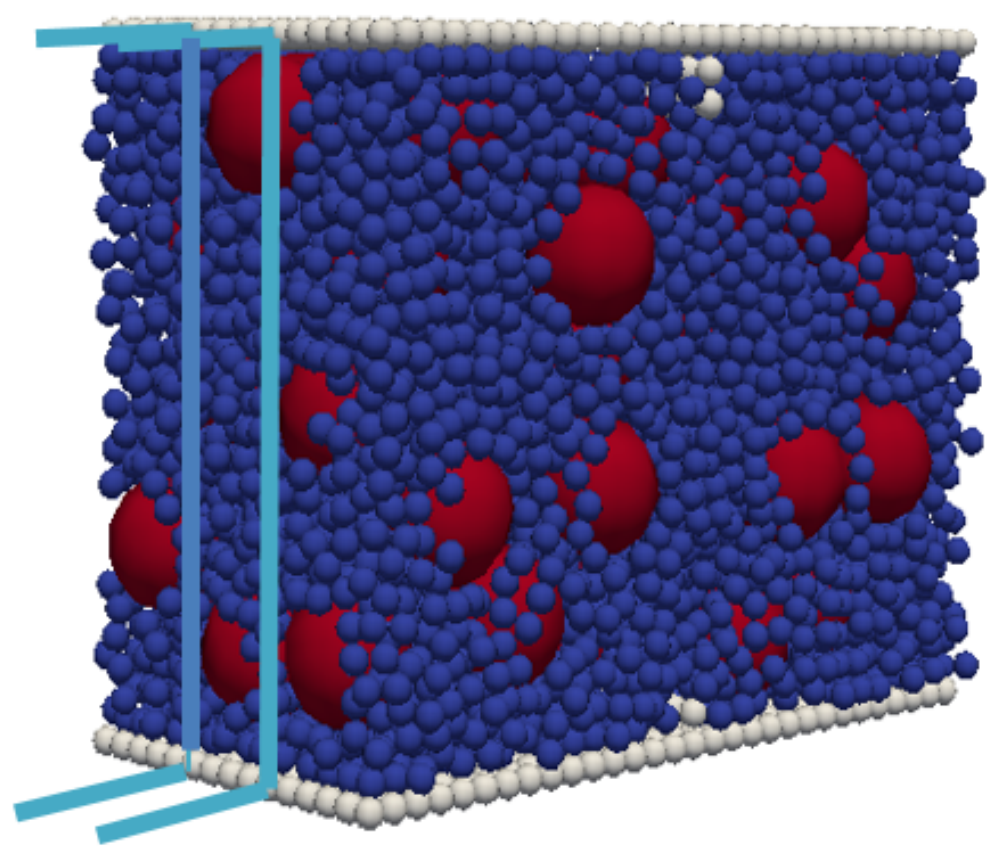

Figure 15. Slice of the computational domain for displaying force chains.

The force chains for L-L contacts are illustrated in Figure 16. For the monodisperse large particles, L-L contacts uniformly exist throughout the particle bed. However, for the binary system, the importance of L-L contacts decreases with decreasing fraction of large particles, as an increased number small particles are involved and play a more significant role in force transmission.

\section{Hosted file}

image19.emf available at https://authorea.com/users/319476/articles/449200-experimental-andnumerical-investigations-of-the-shear-behavior-of-binary-particle-blends

\section{Hosted file}


image20.emf available at https://authorea.com/users/319476/articles/449200-experimental-andnumerical-investigations-of-the-shear-behavior-of-binary-particle-blends

(a) (b)
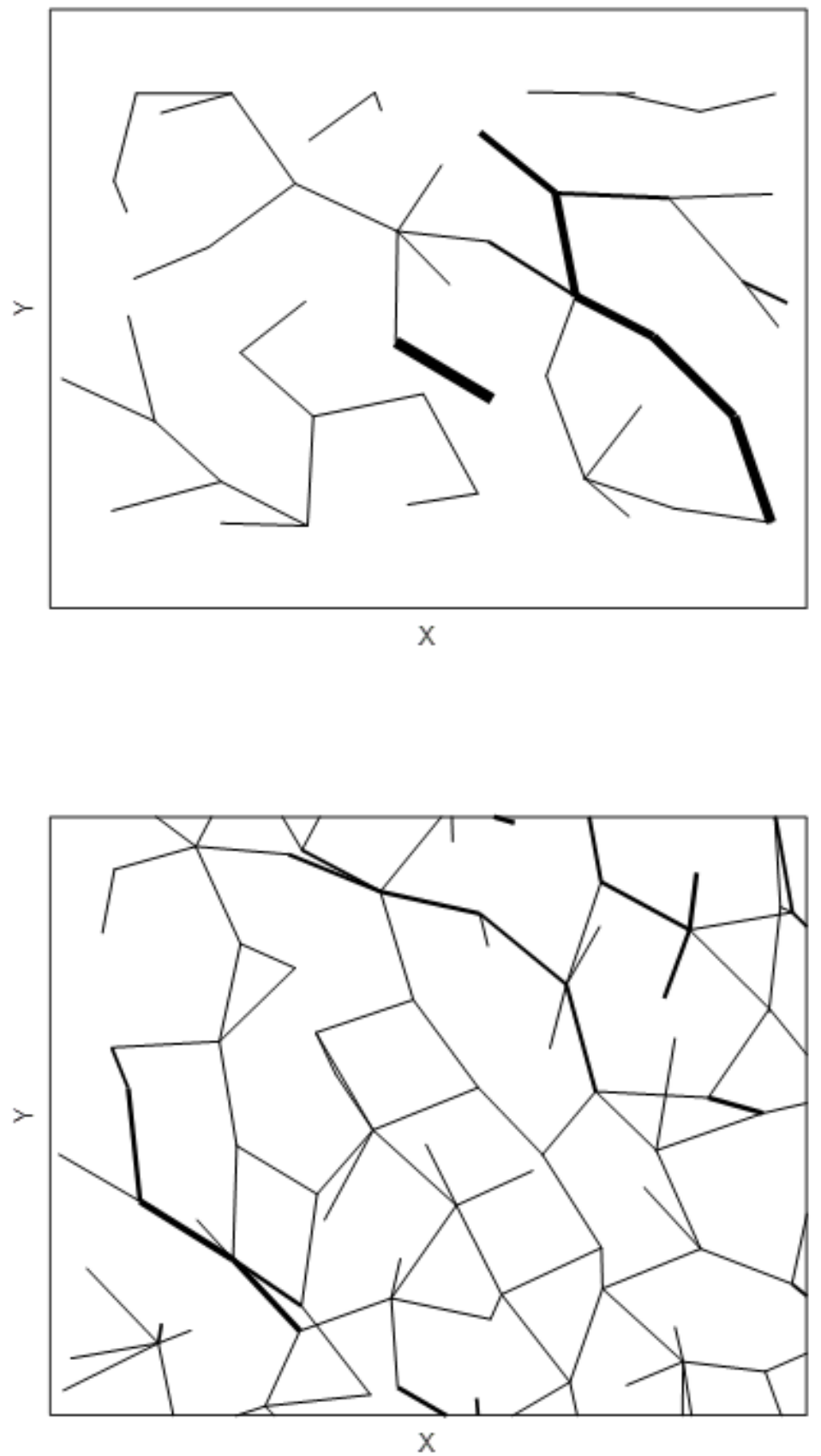

(c) (d) 
Figure 16. Force chain plots for L-L contacts. (a) $25 \%$ large particles; (b) $50 \%$ large particles; (c) $75 \%$ large particles; (d) $100 \%$ large particles.

The force chains for L-L and L-S contacts are illustrated in Figure 17. For the 100\% large system, the L-L contact is the only way for transmitting the force. For binary systems (particularly for the $50 \%$ large and $25 \%$ large mixtures), the L-S contacts are the primary vehicle for force transmission between large particles, as large particles are surrounded by many small particles. For the $75 \%$ large particle systems, small particles fill some gaps between the large particles and both L-L and L-S contacts serve to transmit forces.

\section{Hosted file}

image23.emf available at https://authorea.com/users/319476/articles/449200-experimental-andnumerical-investigations-of-the-shear-behavior-of-binary-particle-blends

\section{Hosted file}

image24.emf available at https://authorea.com/users/319476/articles/449200-experimental-andnumerical-investigations-of-the-shear-behavior-of-binary-particle-blends

(a) (b)

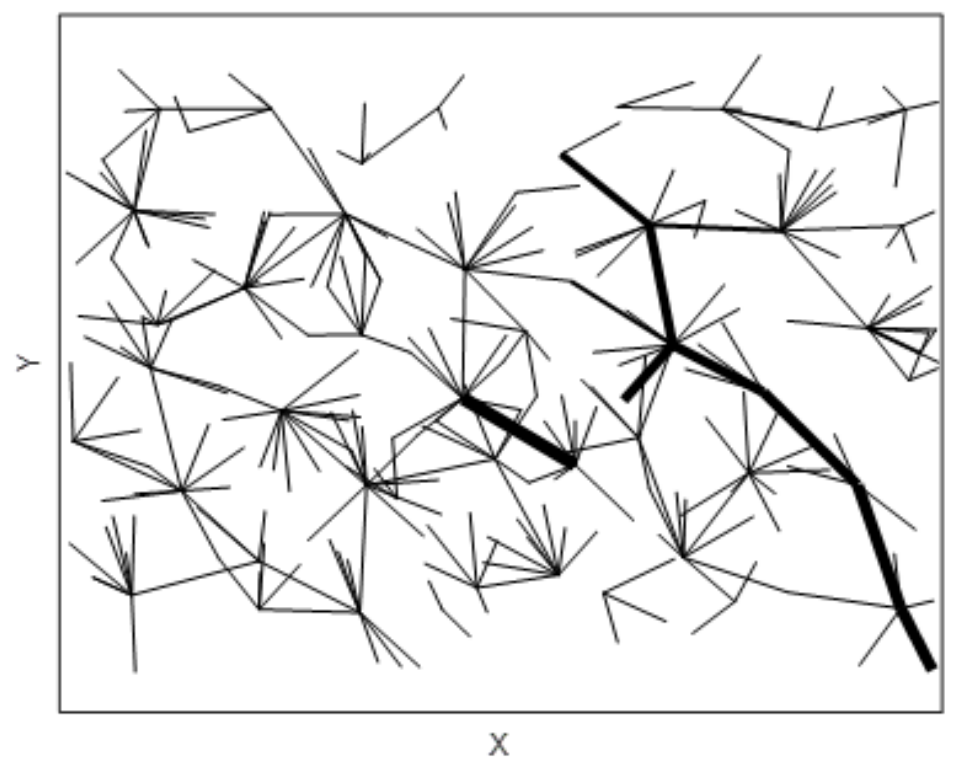




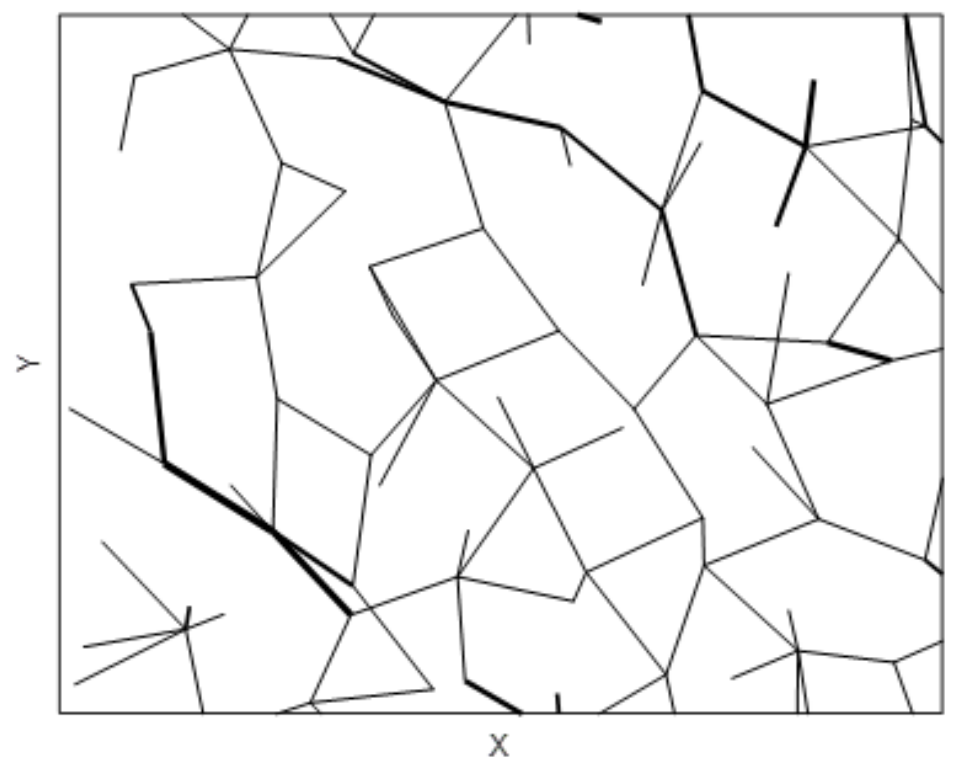

(c) (d)

Figure 17. Force chain plots for L-L and L-S contacts. (a) $25 \%$ large particles; (b) $50 \%$ large particles; (c) $75 \%$ large particles; (d) $100 \%$ large particles.

The force chains for L-L, L-S and S-S contacts are illustrated in Figure 18. For 100\% large and $75 \%$ large particle systems, the effect of S-S contacts is negligible due to the insufficient number of small particles. However, for binary systems with a fraction of large particles at $50 \%$ and $25 \%$, the effect of S-S contacts on force transmission is very significant. When the number of small particles is sufficiently high, large particles are totally separated from each other, immersed in a sea of small particles. The force chain plots of Figure 18 (b) are also consistent with the experimental observation that the bulk flow behavior of the 50:50 mixture is similar to that of small particles only. For both of these particle systems, the S-S contacts are the dominate mechanism for transmitting forces. 

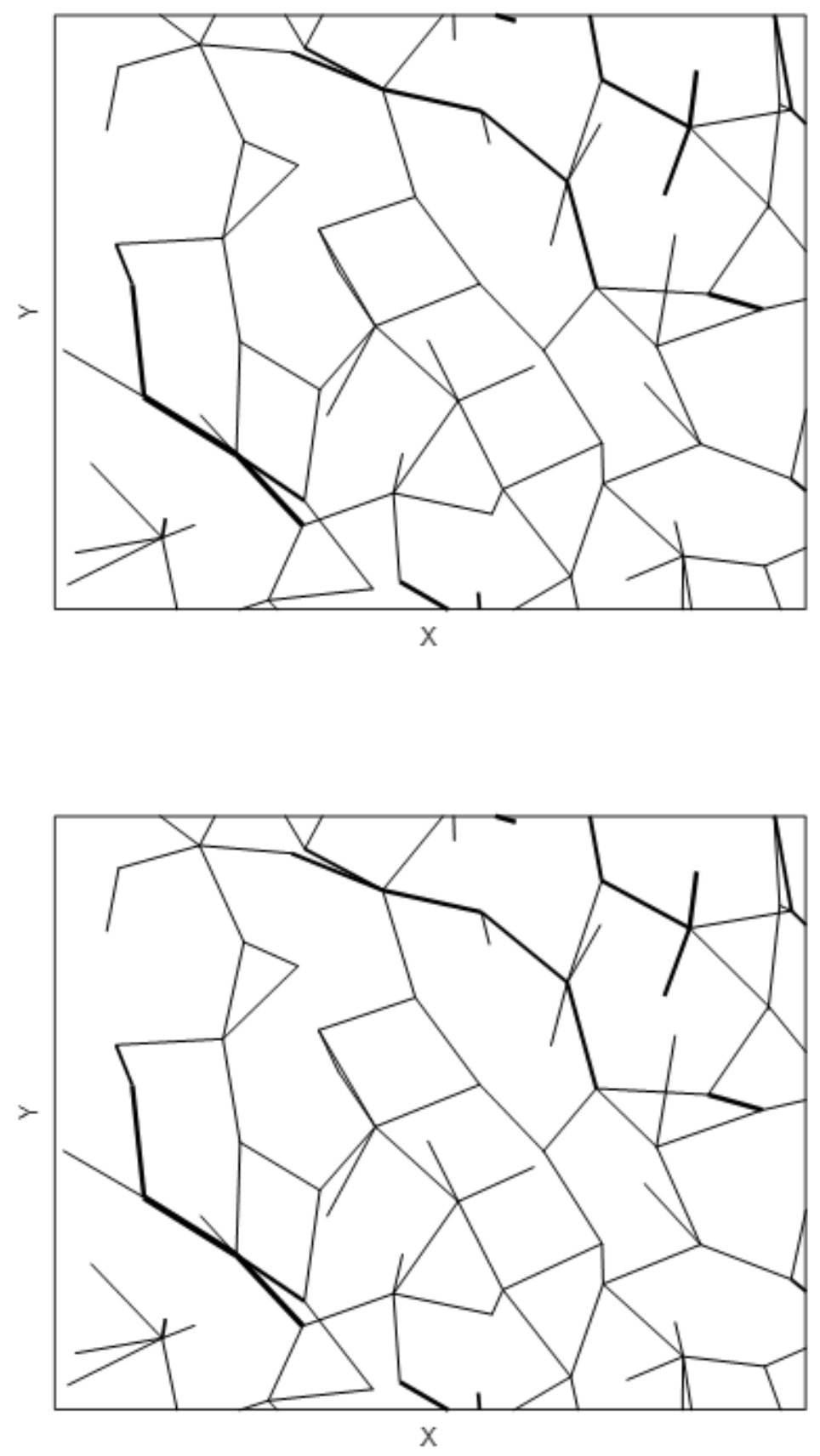

(a) (b)

Hosted file

image28.emf available at https://authorea.com/users/319476/articles/449200-experimental-andnumerical-investigations-of-the-shear-behavior-of-binary-particle-blends

Hosted file 
image29.emf available at https://authorea.com/users/319476/articles/449200-experimental-andnumerical-investigations-of-the-shear-behavior-of-binary-particle-blends

(c) $(\mathrm{d})$

Figure 18. Force chain plots for L-L, L-S and S-S contacts. (a) 25\% large particles; (b) 50\% large particles; (c) $75 \%$ large particles; (d) 100\% large particles.

\section{Conclusions}

The flow behavior of binary mixtures of two sizes of glass beads was investigated using both the Schulze Ring Shear Tester and the Discrete Element Method. Both approaches demonstrate that the shear stresses required to achieve steady state flow are greater for binary blends than they are for monodisperse systems. Moreover, DEM simulations well reproduce the experimental observation that the highest measured shear stress is not associated with the highest measured solid fraction for the range of binary mixtures studied. Experimental data further confirm that the flow function coefficient (FFc) of these mixtures is strongly affected by its solid fraction, with unconfined yield strength directly correlating to this parameter. An analysis of the frictional and tensile components of unconfined yield strength reveals that the powder friction has a slightly higher contribution to powder strength than powder adhesion, and that the frictional component follows the same trend as steady state shear stress with mixture composition. Whereas maximum tensile strength corresponded to maximum solid fraction, steady state shear stresses and internal angle of friction values do not. DEM simulation demonstrate that the addition of small adhesive particles reduces the averaged angular velocity of the larger particles, which makes a contribution to a larger shear stress and internal friction angle for binary blends. Furthermore, particle contact type, contact number and force network vary significantly for different blends. It is believed that these factors also contribute to the shear stress difference for blends of varying composition.

\section{Acknowledgments}

The financial support from Vertex Pharmaceuticals Incorporated is gratefully appreciated.

\section{References}

1. Schulze D. Flow properties of bulk solids. In: Schulze D, ed.Powders and Bulk Solids - Behavior, Characterization, Storage and Flow . New York: Springer-Verlag Berlin Heidelberg; 2008:35-74. doi:10.1007/9783-540-73768-1_3

2. Guo Y, Buettner K, Lane V, et al. Computational and Experimental Studies of Flexible Fiber Flows in a Normal-Stress-Fixed Shear Cell.AIChE J . 2019;65(1):64-74. doi:10.1002/aic.16397

3. Guo Y, Curtis JS. Discrete Element Method Simulations for Complex Granular Flows. Annu Rev Fluid Mech . 2015;47(1):21-46. doi:10.1146/annurev-fluid-010814-014644

4. Yang J, Wu C-Y, Adams M. Numerical modelling of agglomeration and deagglomeration in dry powder inhalers: A review. Curr Pharm Des . 2015;21(40). doi:10.2174/1381612821666151008150845

5. Baran O, DeGennaro A, Ramé E, Wilkinson A. DEM simulation of a schulze ring shear tester. In: AIP Conference Proceedings . Vol 1145. ; 2009:409-412. doi:10.1063/1.3179948

6. Guo Y, Wassgren C, Ketterhagen W, Hancock B, James B, Curtis J. A numerical study of granular shear flows of rod-like particles using the discrete element method. J Fluid Mech . 2012;713:1-26. doi:10.1017/jfm.2012.423 
7. Yang J, Guo Y, Buettner KE, Curtis JS. DEM investigation of shear flows of binary mixtures of nonspherical particles. Chem Eng Sci . 2019;202:383-391. doi:10.1016/j.ces.2019.03.027

8. Ketterhagen WR, Curtis JS, Wassgren CR, Hancock BC. Predicting the flow mode from hoppers using the discrete element method. Powder Technol . 2009;195(1):1-10. doi:10.1016/j.powtec.2009.05.002

9. Simons TAH, Weiler R, Strege S, Bensmann S, Schilling M, Kwade A. A ring shear tester as calibration experiment for DEM simulations in agitated mixers - A sensitivity study. In: Procedia Engineering . Vol 102. Elsevier Ltd; 2015:741-748. doi:10.1016/j.proeng.2015.01.178

10. Remy B, Khinast JG, Glasser BJ. Polydisperse granular flows in a bladed mixer: Experiments and simulations of cohesionless spheres. Chem Eng Sci . 2011;66(9):1811-1824. doi:10.1016/j.ces.2010.12.022

11. Swaminathan V, Kildsig DO. Polydisperse Powder Mixtures: Effect of Particle Size and Shape on Mixture Stability. Drug Dev Ind Pharm . 2002;28(1):41-48. doi:10.1081/DDC-120001484

12. Vallejo LE. Interpretation of the limits in shear strength in binary granular mixtures. Can Geotech $J$. 2001;38(5):1097-1104. doi:10.1139/t01-029

13. Capece M, Ho R, Strong J, Gao P. Prediction of powder flow performance using a multi-component granular Bond number. Powder Technol . 2015;286:561-571. doi:10.1016/j.powtec.2015.08.031

14. Thakur SC, Morrissey JP, Sun J, Chen JF, Ooi JY. Micromechanical analysis of cohesive granular materials using the discrete element method with an adhesive elasto-plastic contact model. Granul Matter . 2014;16(3):383-400. doi:10.1007/s10035-014-0506-4

15. Specht DW. Caking of granular materials: an experimental and theoretical study. 2006.

16. Cundall PA, Strack ODL. A discrete numerical model for granular assemblies. Geotechnique . 1979;29(1):47-65. doi:10.1680/geot.1979.29.1.47

17. Johnson KL, Kendall K, Roberts AD. Surface Energy and the Contact of Elastic Solids. Proc R Soc A Math Phys Eng Sci . 1971;324(1558):301-313. doi:10.1098/rspa.1971.0141

18. Thornton C, Yin KK. Impact of elastic spheres with and without adhesion. Powder Technol . 1991;65(13):153-166. doi:10.1016/0032-5910(91)80178-L

19. Yang J, Wu CY, Adams M. DEM analysis of particle adhesion during powder mixing for dry powder inhaler formulation development. Granul Matter . 2013;15(4):417-426. doi:10.1007/s10035-013-0405-0

20. Wu K, Rémond S, Abriak NE, Pizette P, Becquart F, Liu S. Study of the shear behavior of binary granular materials by DEM simulations and experimental triaxial tests. Adv Powder Technol . 2017;28(9):2198-2210. doi:10.1016/j.apt.2017.05.027

21. Rumpf H. Grundlegende physikalische Probleme bei der Zerkleinerung.Chemie Ing Tech . 1962. doi:10.1002/cite.330341104 